\title{
Small fiber dysfunction in patients with Wilson's disease
}

\author{
Disfunção de fibras finas em pacientes com doença de Wilson \\ Francisco de Assis A. Gondim¹, Davi F. Araújo², Ítalo S. Oliveira², Otoni Cardoso do Vale
}

\begin{abstract}
Objective: Patients with Wilson's disease (WD) may develop a wide variety of neuropsychiatric symptoms, but there are few reports of autonomic dysfunction. Here, we described evidence of small fiber and/or autonomic dysfunction in 4 patients with WD and levodoparesponsive parkinsonism. Method: We reviewed the charts of 4 patients with WD who underwent evaluation for the presence of neuromuscular dysfunction and water-induced skin wrinkling test (SWT). Results: Two men and 2 women ( $33 \pm 3.5$ years) with WD were evaluated. They all had parkinsonism at some point during their disease course. Parkinsonism on patient 4 almost completely subsided with treatment of WD. Two patients had significant sensory and 2 significant autonomic complaints, including syncopal spells. NCS/EMG was normal in all but SWT was abnormal in half of them (mean 4-digit wrinkling of 0.25 and 1). Discussion: A subset of patients with WD exhibit evidence of abnormal skin wrinkling test (small fiber neuropathy).
\end{abstract}

Keywords: autonomic nervous system diseases, small fiber neuropathy, Wilson's disease.

RESUMO

Objetivo: Pacientes com doença de Wilson (DW) podem desenvolver uma ampla variedade de sintomas neuropsiquiátricos, mas existem poucos relatos de disfunção autonômica. Aqui, nós descrevemos evidência de disfunção de fibras finas/autonômica em 4 pacientes com DW e parkinsonismo responsivo à levodopa. Método: Nós revisamos os prontuários de 4 pacientes com DW que foram submetidos a avaliação neuromuscular e ao teste de quantificação do enrugamento cutâneo (TEC). Resultados: Dois homens e 2 mulheres ( $33 \pm 3,5$ anos) com DW foram avaliados. Todos apresentaram parkinsonismo durante o curso de sua doença. Parkinsonismo no paciente 4 quase completamente desapareceu com tratamento da DW. Dois pacientes apresentaram queixas sensitivas e 2 apresentaram queixas autonômicas significativas incluindo episódios de síncope. Eletroneuromiografia foi normal em todos e TEC foi anormal em metade deles (score do TEC nos 4 dedos de 0,25 e 1). Discussão: Um subgrupo de pacientes com DW apresenta evidência de TEC anormal (neuropatia de fibras finas).

Palavras-chave: doenças do sistema nervoso autônomo, neuropatia de pequenas fibras, doença de Wilson.

Wilson's disease (WD) is an autosomal recessive multisystem disorder of the cooper metabolism caused by mutations of the ATP7B gene and associated with a wide variety of neuropsychiatric symptoms. Central nervous system disease with tremor and parkinsonism is more widely described, while involvement of the peripheral nervous system is considered to be rare, but may include polyneuropathy ${ }^{1,2,3,4,5}$. Polyneuropathy may even precede or herald the diagnosis of $\mathrm{WD}^{1}$. Few reports have also described autonomic dysfunction in WD patients $6,7,8,9,10,11,12$. Autonomic dysfunction has been described both in sympathetic and parasympathetic fibers and may include impairment on cardiovascular and sudomotor fibers. In addition, to date, the extension of central and peripheral autonomic involvement has not been adequately studied. Here, we report evidence of small fiber dysfunction detected by skin wrinkling test (SWT) in 2 out of 4 patients with WD who also had levodopa-responsive parkinsonism. Part of this work has been published in abstract form elsewhere ${ }^{13}$.

\section{METHOD}

We conducted a chart review in all patients with WD seen at one of the Movement Disorders outpatient clinics from the Neurology division at the Universidade Federal do

\footnotetext{
'Departamento de Medicina Clínica, Serviço de Neurologia, Universidade Federal do Ceará, Fortaleza CE, Brazil;

Universidade Federal do Ceará, Fortaleza CE, Brazil.

Correspondence: Francisco de Assis Aquino Gondim; Rua Capitão Francisco Pedro, 1290 Rodolfo Teófilo; 60430-370 Fortaleza CE, Brasil;

E-mail: gondimfranc@yahoo.com

Conflicts of interest: There is no conflict of interest to declare.

Support: Coordenação de Aperfeiçoamento de Pessoal de Nivel Superior (Capes), Conselho Nacional de Desenvolvimento Científico e Tecnológico (CNPq) e Universidade Federal do Ceará.

Received 24 August 2013; Received in final form 15 May 2014; Accepted 03 June 2014.
} 
Ceará. We found $4 \mathrm{WD}$ patients that were referred for management of parkinsonism at some point during their disease course. They all underwent neuromuscular evaluation, as part of an ongoing research project to evaluate the neuromuscular complications in all patients with parkinsonism from this clinic. No patient with WD from this clinic was excluded and neuromuscular evaluation was not based on specific neurological complaints.

Water-induced SWT is a test of autonomic/sensory small fiber function that was developed in 1936 by Lewis and Pickering $^{14}$ and provided a simple and unexpensive way to evaluate small fiber function ${ }^{15}$. Patients are asked to keep one hand inside a reservoir with $0.5 \mathrm{mmol}$ of $\mathrm{NaCl}$ at $40.5{ }^{\circ} \mathrm{C}$ for 30 minutes. The total amount of skin wrinkling in 4 fingers is graded by trained observers and a mean score for the 4 fingers is generated. Grading is easier, and abnormal skin wrinkling closely correlated with abnormalities on skin biopsy tests, that is currently the gold-standard for evaluation of small fiber function ${ }^{15}$. Mean wrinkling scores lower than 2 are consistent with small fiber dysfunction ${ }^{15}$. Except for patients with the presence of hand callosities due to manual labor, the test is otherwise very reliable ${ }^{16}$. In a control group consisting of 9 healthy individuals (4 men and 5 women, age range of 18 to 39 years) - to match the age of our WD patients $(22.2 \pm 2.2$ years $)$-, the mean SWT score was $3.7 \pm 0.2$. None of our patients with WD had hand signs that precluded adequate evaluation of skin wrinkling (manual labor or hand deformity/local abnormality) ${ }^{16}$.

At first, our 4 WD patients were clinically evaluated for the presence of neuromuscular diseases and underwent water-induced skin wrinkling testing (SWT) in the outpatient clinic with the methodology described above ${ }^{15}$. Thereafter, nerve conduction studies/electromyography were performed. This study was approved by the Institutional Review Board from the Universidade Federal do Ceará.

\section{RESULTS}

Two men and 2 women (33 \pm 3.5 years) with WD were evaluated. All 4 patients had positive family history of WD (patients 1 and 2 had one affected brother, and patients 3 and 4 had 3 affected brothers). They all had parkinsonism at some point during the disease course (on patient 4 parkinsonism was transient and almost completely subsided with treatment for WD). Two patients had significant sensory complaints and 2 had significant autonomic complaints including syncopal spells (see case reports). All 4 had KayserFleischer rings. Serum ceruloplasmin levels were low in all 4 patients (2.4-3 mg/dL). Nerve conduction studies and electromyography (as needed) were normal in all 4 patients. Water-induced skin-wrinkling test (SWT) was abnormal in half of them (mean 4-digit wrinkling of 0.25 and 1, respectively for patients 1 and 2). No risk factor for peripheral neuropathy was identified in any patient from this series.

The clinical vignettes of the 4 patients will be detailed below.

\section{Patient 1}

A 37 year-old woman presented with cirrhosis at age 33 and was diagnosed with WD and treated with $\mathrm{ZnSO}$, penicillamine and pyridoxine/complex B vitamins. Since age 35 she developed parkinsonism, that was responsive to pramipexole and levodopa. She also complained of burning and numbness in her arms and genital area and urinary incontinence. Her neurological examination revealed ataxic gait, proximal winging beat and resting tremor in the arms with asymmetric rigidity (cogwheel rigidity on the right side), bradykinesia, hyperreflexia with Hoffmann and bilateral Babinski sign (document in at least one visit). In her most recent evaluation, she persisted with bradykinesia (without tremor and cogwheel rigidity), Hoffmann sign persisted bilaterally but she developed generalized hyporreflexia with a flexor plantar response. Normal vibration scores (on RydelSeiffer tuning fork) and mild distal atrophy (intrinsic foot muscles) with right foot dystonia were noted. NCS/EMG was normal but SWT revealed small fiber dysfunction (mean 4-digit wrinkling score of 1). She had no other complaints consistent with sensory or autonomic dysfunction. Based on the medical records, excessive intake of pyridoxine was not evidenced.

\section{Patient 2}

A 23 year-old man was diagnosed with WD at age 14. His mother and father were first degree cousins. He has been treated with penicillamine and pyridoxine since WD was diagnosed. Since age 21, he developed levodopa-responsive parkinsonism, with resting tremor, weight loss, dysphagia and dysphonia. His neurological exam revealed facial hypomimia with bilateral palmo-mental sign, low-amplitude resting tremor, cogwheel rigidity on the right arm, bradykinesia, generalized hyporreflexia, bilateral Babinski sign (not present on his last visit). Normal vibration scores (on Rydel-Seiffer tuning fork) and mild distal atrophy (intrinsic foot muscles) with right foot dystonia were noted. He complained of leg pain for a year. NCS/EMG was normal but water-induced SWT was abnormal (mean 4-digit wrinkling score of 0.25). Brain MRI revealed iron deposits on bilateral basal ganglia and midbrain. He had no other complaints consistent with peripheral neuropathy or autonomic dysfunction. Based on the medical records, excessive intake of pyridoxine was not evidenced.

\section{Patient 3}

A 34 year-old man presented with psychosis and marked behavioral dysfunction followed by levodopa-responsive par- 
kinsonism, dysphagia and episodes of loss of consciousness (syncopal spells). Syncopal spells were only present prior to the diagnosis of WD. Since he had no other autonomic complaints during our evaluation, tilting test was never performed, although he had no orthostatic hypotension and ECGs were normal. Therefore, the exact etiology of the syncopal spells can only be speculated as vasovagal or due to transient autonomic dysfunction prior to our evaluation (history was suggestive of a vasovagal spell). He had a positive family history for WD and was treated with penicillamine and complex B vitamins. His neurological exam revealed facial hypomimia, bradykinesia with bilateral cogwheel rigidity (more prominent on the right), hyporreflexia but no Babinski sign. No signs of peripheral neuropathy or myopathy were present. NCS/EMG and water-induced SWT was normal (mean 4-digit wrinkling score of 4). Brain MRI revealed hypointense signal changes on bilateral basal ganglia. He had no other autonomic or sensory complaints.

\section{Patient 4}

A 38 year-old woman presented with liver dysfunction, behavioral changes, dysphagia and parkinsonism (resting tremor in the upper extremities and akinetic-rigid state) at age 24 and was diagnosed with WD. She was initially treated with penicillamine and biperiden. Parkinsonism almost completely subsided after treatment with penicillamine and she discontinued biperiden. On her last neurological exam, she had only mild postural and winging beat tremor, but no other signs of parkinsonism. No signs of peripheral neuropathy or myopathy were present. Water-induced SWT was normal (mean 4-digit wrinkling score of 3.6). She had no other complaints consistent with sensory or autonomic dysfunction.

\section{DISCUSSION}

WD is associated with a wide variety of neuropsychiatric symptoms. Peripheral neuropathy has been rarely reported, but it may even precede the diagnosis of $\mathrm{WD}^{1,2,3,4,5}$.

In this paper, we report clinical evidence of autonomic and/or sensory small fiber dysfunction as detected by abnormal skin wrinkling test in 2 out of 4 patients with WD and levodopa-responsive parkinsonism (patients 1 and 2). All of our 4 patients had normal nerve conduction studies/electromyography. Half of them (patients 1 and 2) had impaired water-induced skin wrinkling test (mean scores of 1 and 0.25 , respectively) suggesting that a subset of WD patients with levodopa-responsive parkinsonism may also exhibit evidence of small fiber dysfunction. In our series, these abnormalities on SWT correlated with sensory but not with autonomic complaints since patient 3 also had autonomic complaints but no SWT impairment. Therefore, this reinforces the possible peripheral involvement in patients 1 and 2 (with impaired SWT), while clinically patient 3 most likely had autonomic impairment due to central involvement (see case vignettes). One could argue that maybe the technique of SWT has not been validated in all ages ${ }^{14,15,16}$. However, our patients had a narrow age range (23-38 years) and unequivocal/marked abnormalities on skin wrinkling (mean scores of 1 and 0.25), far below the minimum mean SWT score of 2, as reported by Teoh et al..$^{14}$ and also far below the mean SWT scores from our control group: $3.7 \pm 0.2$. In addition, despite the marked SWT abnormality on patients 1 and 2 (mean SWT scores of 0.25 and 1), they had no other signs or complaints suggestive of autonomic dysfunction, especially of central origin, thus reinforcing the possible peripheral nervous system involvement. No other risk factors for peripheral neuropathy or common causes of autonomic dysfunction were detected in our patients. This suggests that the autonomic dysfunction was due to WD, although other uncommon co-morbidities (especially secondary to WD treatment) could not completely be ruled out.

There are few reports of autonomic dysfunction in WD patients $^{6,7,8,9,10,11}$. Autonomic dysfunction has been described both in sympathetic and parasympathetic fibers and may include impairment on cardiovascular and sudomotor fibers. Chu et al. reported abnormalities on sympathetic skin responses in more than half of the WD patients, while $12 \%$ had parasympathetic abnormalities evidenced by forced deep breathing ${ }^{6}$. They postulated that central sympathetic fibers were mainly involved. Autonomic symptoms were usually mild. Abnormal sweating and thermoregulatory control were the most prevalent symptoms. No patient had orthostatic hypotension. Meenakshi-Sundaram S et al. also claimed that autonomic dysfunction was of central origin. However, their conclusion was only supported by normal nerve conduction studies and abnormal sympathetic skin responses and heart rate variability, leaving this subject uncertain to date ${ }^{12}$.

Similar to previous series, none of our 4 patients had orthostatic hypotension. Patient 3 had syncopal spells (clinically consistent with vasovagal syncope) but normal SWT indicating a possible central source of autonomic impairment. However, most of the abnormalities on SWT correlated with clinically relevant sensory complaints, confirming the peripheral involvement (small fiber dysfunction). Unfortunately, we don't have skin biopsy testing available for evaluation of small fiber neuropathies in our institution. This is the gold standard technique at most centers worldwide to evaluate small fiber function ${ }^{17}$. In addition, we could not perform other reliable autonomic tests, such as QSART/ QSweat or quantitative sensory testing, or other tests such as evaluation of the presence of sympathetic skin responses 
(although this latter technique is neither sensitive nor specific for the evaluation of small fiber dysfunction).

Considering the above limitations and the small sample of the present study, it was not possible to establish whether the autonomic dysfunction was secondary to liver dysfunction, due to other rare metabolic disorders or occurred as a direct complication of WD. In addition, although previous reports have suggested a central explanation for the autonomic involvement in WD patients, our present findings together with the results from von Giesen et al. ${ }^{9}$ suggest that unmyelinated C-fibers (small fiber neuropathy) are affected in a subset of WD patients with levodopa-responsive parkinsonism. Further studies are necessary to outline the exact pathways, the extent of autonomic and small fiber impairment in patients with WD patients, since we have not disclosed any abnormality on the most common metabolic tests employed for the diagnosis of peripheral neuropathy or autonomic dysfunction.

\section{References}

1. Jung K, Ahn T, Jeon BS. Wilson disease with an inital manifestation of polyneuropathy. Arch Neurol 2005;62:1628-1631.

2. Miyakawa T, Murayama E, Sumiyoshi S, et al. A biopsy case of Wilson's disease. Pathological changes in peripheral nerves. Acta Neuropathol 1973;24:174-177.

3. Leven B, Fasshauer K. Lesions of the peripheral nerves in Wilson's disease. Electrodiagnostic findings. Fortschr Neurol Psychiatr Grenzgeb 1978;46:202-206.

4. Madden JW, Ironside JW, Triger DR, Bradshaw JP. An unusual case of Wilson's disease. Q J Med 1985;55:63-73.

5. Cortese A, Zangaglia R, Lozza A, et al. Cooper deficiency in Wilson's disease: peripheral neuropathy and myelodisplastic syndrome complicating zinc treatment. Mov Disord 2011;26:1361-1362.

6. Chu EC, Chu N, Huang C. Autonomic involvement in Wilson's disease: a study of sympathetic skin response and RR interval variation. J Neurol Sci 1997;149:131-137

7. Brewer GJ. Autonomic dysfunction in Wilson's disease. Clin Auton Res 2002;12:139-140.

8. Soni D, Shukla G, Singh S, et al. Cardiovascular and sudomotor autonomic dysfunction in Wilson's disease-limited correlation with disease severity. Aut Neurosci 2009;151:154-158.

9. Von Giesen H-J, Weiss P, Arendt G, Hefter H. Potential C-fiber damage in Wilson's disease. Acta Neurol Scand 2003;108:257-261.
10. Deguchi K, Sasaki I, Touge T, et al. Improvement of cardiovascular autonomic dysfunction following anti-copper therapy in Wilson's disease. J Neurol 2005;252:495-497.

11. Kumar S. Severe autonomic dysfunction as a presenting feature of Wilson's disease. J Postgrad Med 2005;51:75-76.

12. Meenakshi-Sundaram S, Taly AB, Kamath $V$, et al. Autonomic dysfunction in Wilson's disease-a clinical and electrophysiological study. Clin Auton Res 2002;12:185-189.

13. Gondim FAA, Araújo DF, Oliveira IS, et al. Levodopa-responsive parkinsonism and small fiber dysfunction in patients with Wilson's disease. Mov Disord 2013;28(Suppl):S351-S352.

14. Lewis T, Pickering GW. Circulatory changes in the fingers in some diseases of the nervous system, with special reference to atrophy of peripheral nerve lesions. Clin Sci 1936;2:149-175.

15. Teoh HL, Chow A, Wilder-Smith EP. Skin wrinkling for diagnosing small fiber neuropathy: comparison with epidermal nerve density and sympathetic skin response. J Neurol Neurosurg Psych 2008;79:835-837.

16. Clark CV, Pentland B, Ewing QJ, Clarke BF. Decreased skin wrinkling in diabetes mellitus. Diab Care 1984;7:224-227.

17. Gondim FAA, Brannagan TH 3rd, Sander HW, et al. Peripheral neuropathy in patients with inflammatory bowel disease. Brain 2005;128:867-879. 